\title{
A cross sectional study on psychological impact of covid19 on post graduate doctors and Compulsory Rotatory Residential interns in COVID isolation ward of a tertiary care centre, Madurai
}

\author{
P.N. Sridevi *, M. Selvameena, S. Priya, Mohamed Saleem, R. Saran \\ Institute of Community Medicine, Madurai Medical College, Madurai, Tamil Nadu, India
}

A R T I C L E I N F O

\section{Keywords:}

COVID-19

Healthcare workers

Depression

Anxiety

Stress

\begin{abstract}
A B S T R A C T
Background: COVID-19 pandemic causes major impact on economic, physical, mental well-being of people all over the world. Doctors are working in stressful, unprepared, limited resource setting, and they are under the continuous threat of getting infection. Managing mental health of these warriors is great importance. Hence the present study to estimate the psychological impact of COVID-19* and factors associated with it among doctors in tertiary care hospital, Madurai.

Methods: A Cross-sectional study was conducted during October-November 2020 using a pre-designed semi structured questionnaire and DASS-21 scale which were sent through Google form to doctors who were in their quarantine period after the COVID duty. Totally 292 responses were received. Descriptive statistics done to find frequencies and percentages. Correlation for continuous variables; Univariate and multivariate regression for categorical variables were used to predict the factors influencing the psychological impact.

Results: In our study, $42.1 \%$ doctors were depressed, $43.8 \%$ were stressed and $50.7 \%$ had anxiety. Depression*, anxiety*, stress* scores were positively correlated with number of COVID duties $\left(\mathrm{r}^{2} 0.163,0.138,0.133\right)$, number of elderly persons $\left(\mathrm{r}^{2} 0.188,0.169,0.188\right)$ in their family and negatively correlated with sleep duration $\left(\mathrm{r}^{2}-0.219\right.$,$0.281,-0.239)$, attitude of study participants $\left(\mathrm{r}^{2}-0.319,-0.274,-0.291\right)$. Multiple logistic regression showed that disturbed sleep(odd'sratio $=3.931,2.734,3.420$ ) and poor quality of sleep which affect the next day function (odd'sratio $=3.470,2.968,3.122$ ) were significant predictors for all three psychological impacts.

Conclusion: High prevalence of psychological impact estimated, ensures the requirement of early screening with timely psychological intervention and establishment of guideline policies to support mental health of healthcare workers* for maintaining the functionality of healthcare system.
\end{abstract}

\section{Introduction}

There have been many epidemics in the recent past like SARS, Ebola, MERS etc., COVID 19 has quickly gained the attention of the world as it transcended from a WHO declared Public Health Emergency to a "Pandemic" status in the span of couple of months in March 11, 2020. ${ }^{1}$ As on Jan. 22, 2021 a total of 96.2 Million infected cases with 2 Million deaths were reported in 222 countries. $^{2}$ The status of India as on 22 nd Jan., 2021 is, 10.6 Million were infected with 153 thousand deaths, and the State of Tamil Nadu ranks second in the country. ${ }^{3}$

COVID-19 pandemic has caused a world-wide negative health impact among all populations and cross-sections of the society. The front line workers particularly the Health Care workers (HCWs) stand to face the major impact of such a global disaster. Major challenges that the HCWs face during this pandemic are their work load; increased demand for personal protective equipment(PPE); sparse data availability on the disease biology; disease severity; disease/risk management; fear of infection for self and their family members; stigma; inability to cope with unfounded social media propagandas etc. ${ }^{4}$ In addition, HCWs experience increased infection rate and high mortality, for e.g. the mortality rate among HCWs during COVID pandemic is higher than SARS and MERS mortality rates combined..$^{5}$ As a result, HCWs develop psychological disorders related to anxiety, depression and stress as reported during SARS outbreak. ${ }^{6}$

Lancee et al., 2008 has reported both short term and long term effects such as burnout, traumatic stress, anxiety and depression among HCWs

\footnotetext{
* Corresponding author.

E-mail address: drselvameena2@gmail.com (P.N. Sridevi).
} 
and stressed the need for the medical care of HCWs for their mental wellness. $^{7} 32 \%$ of HCWs reported depression during COVID-19 pandemic compared to a mere $10 \%$ reported depression among common public. ${ }^{8}$ In a study from china stress, anxiety, depression and insomnia were at a rate of $73.4 \%, 44.7 \%, 50.7 \%$ and $36.1 \%$ respectively among HCWs during COVID pandemic. ${ }^{9}$ Studies done in India showed alarmingly high number of health care workers experiencing mental overload ( $>40 \%$ prevalence) during this pandemic indicating that healthcare workers are the worst affected by the pandemic. ${ }^{10-12}$ So this study was planned to understand the various psychological effects of COVID 19 pandemic in doctors working in tertiary care centre. It will provide the basis for further studies and guide the policy makers to provide guidelines for early screening and implementation of intervention programme for healthcare workers.

\section{Objective}

1. To estimate the prevalence of various psychological impacts (depression, anxiety, stress) of COVID 19 among Compulsory Rotatory Residential interns (CRRI's) and Postgraduates (PG) working in a tertiary care centre, Madurai

2. To determine the factors associated with these psychological impacts.

\section{Materials and methods}

A cross-sectional study was conducted among CRRI's and PG's of a tertiary care centre, who had completed their COVID duty. The study was conducted for two months from the month of October 2020 to November 2020. Our Institution is a tertiary care hospital which had received cases from nearby districts and also has admitted all types of COVID cases ranging from asymptomatic to severe cases. PGs and CRRI's who got an exemption from COVID duty; those who were on antidepressants and those who had not responded even after 3 reminders were excluded from the study. Sampling technique was not used. All doctors who performed COVID duty during our study period were included. Out of 368 doctors who have attended COVID duty at least one time during the study period, only 292 responded.

A validated predesigned semi-structured questionnaire was used for data collection. The questionnaire had two parts. The first part had questions to collect data on age, gender, educational qualification (UG/ PG), PG speciality, marital status, number of children and elder persons in their family, history of known medical illness, intake of antidepressant, number of COVID duties done so far, time interval between duties, COVID related symptoms after COVID duty, COVID positivity status, sleep disturbances, duration of sleep. It also had questions to assess the attitude like satisfaction with safety precaution, worry about getting infected by COVID, worry about the source of infection. In second section, validated Depression, Anxiety, and Stress Scale 21 (DASS-21) was included. ${ }^{13-16}$ DASS-21 questionnaire was designed to measure the emotional states like depression, anxiety, stress over the past 1 week. DASS 21 scales had 3 subscales in which each subscale consists of 7 questions. Each question had 4 point likert scale. The scale of depression assesses feelings of hopelessness, loss of interest and pleasure, dysphoria, self-deprecation, etc. The anxiety scale measures autonomic arousal, subjective, situational aspects of anxiety, etc. The stress scale assesses aspects such as inability to relax, being easily upset or irritated, and being impatient or over reactive. The rating scale was as follows: 0 Did not apply to me at all, 1 - Applied to me to some degree, or some of the time, 2 - Applied to me to a considerable degree or a good part of time, 3 - applied to me very much or most of the time. The final score for the shorter version was multiplied by two to obtain the cumulative score.

Institute ethical committee approval was obtained for this study. Confidentiality was maintained throughout the period of study. All PGs and CRRIs in our hospital who were quarantined after completing
COVID duty were contacted through the telephone and were informed about the study objectives. After getting consent, questionnaire was sent through Google forms. Reminder messages were sent to all the study participants after one week irrespective of their response and thereafter once in every 3 days. The data collected in Google form was downloaded as excel format and Statistical analysis was done using SPSS version 21 and figures were drawn in Microsoft word. Descriptive statistics was used to find out the frequencies and percentages. To find out the association between two quantitative variables, spearman correlation test was done. To find out the association between two qualitative variables, chi-square test was used. Binary and multiple logistic regressions were used to find out the predictors of mental health outcome through unadjusted and adjusted odd's ratio respectively. For all the comparisons, $\mathrm{p}<0.05$ was considered statistically significant.

\section{Results}

Fig. 1 shows the distribution of age and gender of study participants. Mean age with standard deviation of study participants was $25.98 \pm 4.25$ in years. Out of 292 study participants 138 (47.3\%) were males, 154 (52.7) were females. Majority $90.8 \%(\mathrm{n}=265)$ were under the age of 30 .

Fig. 2 shows the distribution of depression, anxiety, and stress among doctors. Among the study participants, 123(42.1\%) doctors were depressed, 39(13.4\%) had mild and 41(14\%), 21(7.2\%), 22(7.5\%) were had moderate, severe, extremely severe depression respectively. 128 (43.8\%) doctors were stressed, $79(27.1 \%)$ had mild stress and $29(9.9 \%)$ had moderate stress, $13(4.5 \%)$ had severe stress, and $7(2.4 \%)$ doctors were had very severe stress. Out of the total 292 study participants, 148 (50.7\%) were found to have anxiety and 28(9.6\%), 64(21.9\%), 21 $(7.2 \%)$, and $35(12 \%)$ participants had mild, moderate, severe, and extremely severe anxiety, respectively.

Table 1 Shows association between depression and various factors using chi-square and binary logistic regression. Proportion of depressed was found to be high in females $70(45.5 \%)$ than males $53(38.4 \%)$. However this was not statistically significant. Compared to undergraduates, proportion of postgraduates depressed was $49.2 \%$ which was statistically significant with p-value of $<0.001$, unadjusted odd's ratio $0.398(0.235-0.673)$. Postgraduates belonged to clinical speciality, nonclinical speciality had 6 times and 2 times higher risk of developing depression than undergraduates and it was statistically significant. Risk of depression among doctors with chronic medical illness was 2.5 times higher than those without chronic medical illness and it was statistically significant. Out of 292 study participants, 11 did not attend the COVID training. Among them $9(81.8 \%)$ had depression symptoms which was comparatively higher than those who attended COVID training (40.6\%). Risk of depression among doctors who developed COVID symptoms after their COVID duty was 2.3 times higher than those who did not developed COVID symptoms. Among 292 study participants, 25 doctors

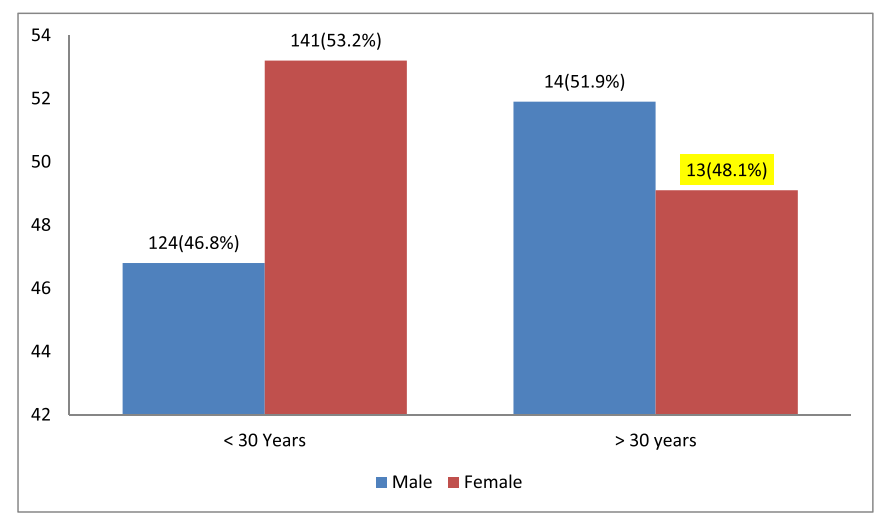

Fig. 1. Distribution of Age and Gender of respondents $(n=292)$. 


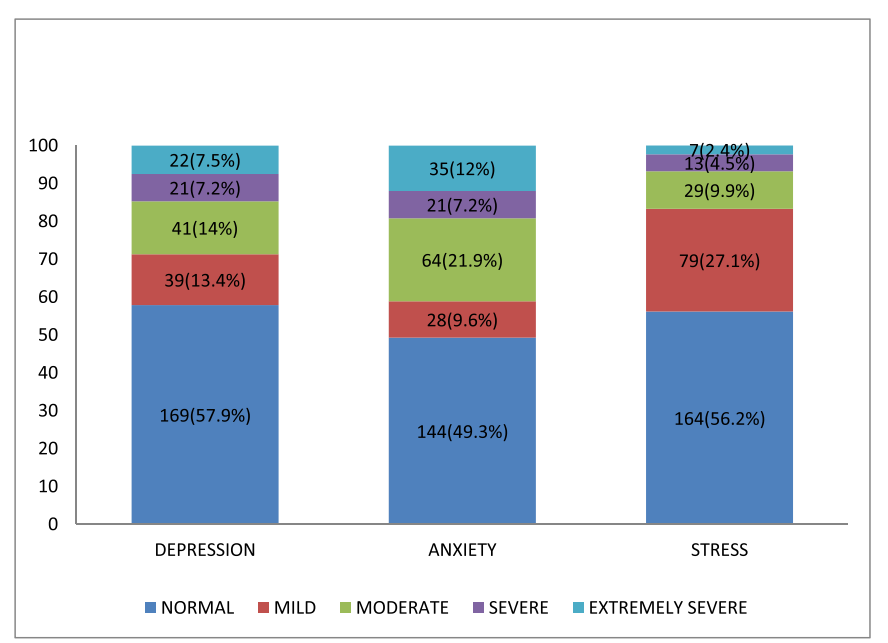

Fig. 2. Distribution of depression, Anxiety, Stress among Doctors $(n=292)$.

became COVID positive, among which $52 \%$ were found to have depression and proportion of depressed among doctors who did not became COVID positive was $41.2 \%$. Doctors with sleep disturbances (63.6\%), those who had poor quality of sleep affecting the next day function $(51.9 \%)$ were predicted to have significantly higher risk of developing depression than their counterpart.

Table 2 shows the association between anxiety and various factors using chi-square and binary logistic regression. Proportion of Doctors with anxiety among females was $54.5 \%$ and males was $46.4 \%$, but this was not statistically significant. Postgraduates (54.9\%) had significantly higher risk of developing anxiety than undergraduates (42.3\%). Compared to undergraduates, clinical postgraduates had 3.2 times higher risk of developing anxiety which was statistically significant. But nonclinical postgraduates had only 1.56 times higher risk than undergraduates, and it was not significant. Proportion of doctors who developed anxiety among those with chronic medical illness (63.2\%), who developed symptoms after COVID duty (59.7\%), who had sleep disturbances $(63.6 \%)$, who had poor quality of sleep affecting the next day function (53.5\%) were higher than their counterparts and they were also statistically significant. Even though the proportion of doctors found to have anxiety among those who did not attend COVID training before duty and among those who became positive after their COVID duty were higher than their counterparts, they were not statistically significant.

Table 3 shows the association between stress and various factors using chi-square and binary logistic regression. Out of 292 study participants 148 had stress symptoms. Percentage of females doctors stressed was $54.5 \%$ and male doctors were $46.4 \%$ which was not statistically significant. Postgraduates had significantly higher risk of developing stress than undergraduates. Clinical postgraduates had 2.7 times higher risk ( $p$ value - 0.058), and nonclinical postgraduates had 1.7 times higher risk of developing stress ( $p$ value - 0.029) than undergraduates. Doctors who developed symptoms after COVID duty had 2.2 times higher risk of developing stress than those who did not developed symptoms and also doctors with sleep disturbances had 4.4 times higher risk and doctors with poor quality of sleep affecting the next day function had 4.7 times higher risk of developing stress than their counterparts. Factors like marital status, chronic medical illness, COVID training before duty, becoming COVID positive after COVID duty were not significantly associated with stress.

Table 1

Association between Depression and Various Risk factors among study participants $(\mathrm{n}=292)$.

\begin{tabular}{|c|c|c|c|c|c|}
\hline FACTORS & $\begin{array}{l}\text { DEPRESSED } \mathrm{n}=123 \\
(\%)\end{array}$ & $\begin{array}{l}\text { TOTAL } \mathrm{n}=292 \\
(\%)\end{array}$ & $\begin{array}{l}\text { CHI-SQUARE P- } \\
\text { VALUE }\end{array}$ & $\begin{array}{l}\text { P- VALUE BY BINARY LOGISTIC } \\
\text { REGRESSION }\end{array}$ & $\begin{array}{l}\text { UNADJUSTED ODD'S RATIO (95\% } \\
\text { CI) }\end{array}$ \\
\hline \multicolumn{6}{|l|}{ GENDER } \\
\hline Male $^{r}$ & $53(38.4)$ & $138(100)$ & & & \\
\hline Female & $70(45.5)$ & 154(100) & 0.223 & 0.224 & $1.336(0.838-2.132)$ \\
\hline \multicolumn{6}{|c|}{ EDUCATIONAL QUALIFICATION } \\
\hline Undergraduate $^{r}$ & $27(27.8)$ & $97(100)$ & & & \\
\hline Postgraduate & $96(49.2)$ & 195(100) & $0.000^{*}$ & $0.001^{*}$ & $2.514(1.487-4.251)$ \\
\hline \multicolumn{6}{|c|}{ TYPE OF SPECIALITY } \\
\hline Clinical & $84(47.2)$ & $166(100)$ & & & \\
\hline Nonclinical & $12(70.6)$ & $17(100)$ & & $0.002 *$ & $6.222(2.002-19.336)$ \\
\hline Undergraduates $^{r}$ & $27(27.8)$ & $97(100)$ & $0.000^{*}$ & $0.002 *$ & $2.317(1.360-3.947)$ \\
\hline \multicolumn{6}{|c|}{ MARITAL STATUS } \\
\hline Unmarried $^{\mathrm{r}}$ & $100(42.5)$ & $233(100)$ & & & \\
\hline Married & $23(39)$ & $59(100)$ & 0.584 & 0.585 & $0.850(0.474-1.524)$ \\
\hline \multicolumn{6}{|c|}{ H/O CHRONIC MEDICAL ILLNESS } \\
\hline $\mathrm{No}^{\mathrm{r}}$ & $111(40.7)$ & $273(100)$ & & & \\
\hline Yes & $12(63.2)$ & 19(100) & 0.053 & 0.062 & $2.502(0.955-6.553)$ \\
\hline \multicolumn{6}{|c|}{ COVID TRAINING BEFORE DUTY } \\
\hline Yes $^{r}$ & $114(40.6)$ & $281(100)$ & & & \\
\hline No & $9(81.8)$ & 11(100) & $0.007^{*}$ & $0.017^{*}$ & $6.592(1.398-31.076)$ \\
\hline \multicolumn{6}{|c|}{ DEVELOP SYMPTOMS AFTER COVIDDUTY } \\
\hline $\mathrm{No}^{\mathrm{r}}$ & $87(37.8)$ & $230(100)$ & & & \\
\hline Yes & $36(58.1)$ & $62(100)$ & $0.004^{*}$ & $0.005^{*}$ & $2.276(1.286-4.026)$ \\
\hline \multicolumn{6}{|c|}{ BECAME COVID POSITIVE AFTER COVIDDUTY } \\
\hline $\mathrm{No}^{\mathrm{r}}$ & $110(41.2)$ & $267(100)$ & & & \\
\hline Yes & $13(52)$ & $25(100)$ & 0.296 & 0.299 & $1.545(0.680-3.516)$ \\
\hline \multicolumn{6}{|c|}{ SLEEP DISBURBANCES } \\
\hline $\mathrm{No}^{\mathrm{r}}$ & $41(25.2)$ & $163(100)$ & & & \\
\hline Yes & $82(63.6)$ & $129(100)$ & $0.000^{*}$ & $0.000 *$ & $5.191(3.137-8.591)$ \\
\hline \multicolumn{6}{|c|}{ FALL ASLEEP IF WAKE UP IN NIGHT } \\
\hline Yes $^{r}$ & $84(41)$ & 205(100) & & & \\
\hline No & $39(44.8)$ & $87(100)$ & 0.542 & 0.542 & $1.170(0.706-1.941)$ \\
\hline \multicolumn{6}{|c|}{ QUALITY OF SLEEP AFFECT THE NEXT FUNCTION } \\
\hline $\mathrm{No}^{\mathrm{r}}$ & $14(17.1)$ & $82(100)$ & & & \\
\hline Yes & 109(51.9) & $210(100)$ & $0.000^{*}$ & $0.000^{*}$ & $5.242(2.776-9.899)$ \\
\hline
\end{tabular}

*- significant p-value $(<0.05)$.

${ }^{\mathrm{r}}$ Reference group. 
Table 2

Association between Anxiety and Various Risk factors among study participants $(\mathrm{n}=292)$.

\begin{tabular}{|c|c|c|c|c|c|}
\hline FACTORS & ANXIETY $\mathrm{n}=148(\%)$ & TOTAL n = 292(\%) & $\begin{array}{l}\text { CHI-SQUARE } \\
\text { P-VALUE }\end{array}$ & P- VALUE BY BINARY LOGISTIC REGRESSION & UNADJUSTED ODD'S RATIO (95\% CI) \\
\hline \multicolumn{6}{|l|}{ GENDER } \\
\hline Male $^{r}$ & $64(46.4)$ & $138(100)$ & & & \\
\hline Female & $84(54.5)$ & $154(100)$ & 0.163 & 0.164 & $1.387(0.875-2.200)$ \\
\hline \multicolumn{6}{|c|}{ EDUCATIONAL QUALIFICATION } \\
\hline Undergraduate $^{r}$ & $41(42.3)$ & $97(100)$ & & & \\
\hline Postgraduate & 107(54.9) & 195(100) & $0.042 *$ & $0.043^{*}$ & $1.661(1.016-2.716)$ \\
\hline \multicolumn{6}{|c|}{ TYPE OF SPECIALITY } \\
\hline Clinical & $95(53.4)$ & $178(100)$ & & & \\
\hline Nonclinical & $12(70.6)$ & $17(100)$ & & $0.037^{*}$ & $3.278(1.071-10.030)$ \\
\hline Undergraduates $^{r}$ & $41(42.3)$ & $97(100)$ & 0.051 & 0.079 & $1.563(0.949-2.575)$ \\
\hline \multicolumn{6}{|c|}{ MARITAL STATUS } \\
\hline Unmarried $^{r}$ & $115(49.4)$ & 233(100) & & & \\
\hline Married & $33(55.9)$ & $59(100)$ & 0.367 & 0.368 & $1.302(0.733-2.313)$ \\
\hline \multicolumn{6}{|c|}{ H/O CHRONIC MEDICAL ILLNESS } \\
\hline $\mathrm{No}^{\mathrm{r}}$ & 133(48.7) & 273(100) & & & \\
\hline Yes & 15(78.9) & 19(100) & $0.011^{*}$ & $0.017^{*}$ & $3.947(1.277-12.197)$ \\
\hline \multicolumn{6}{|c|}{ COVID TRAINING BEFORE DUTY } \\
\hline Yes $^{r}$ & $140(49.8)$ & 281(100) & & & \\
\hline No & $8(72.7)$ & $11(100)$ & 0.136 & 0.151 & $2.686(0.698-10.333)$ \\
\hline \multicolumn{6}{|c|}{ DEVELOP SYMPTOMS AFTER COVIDDUTY } \\
\hline $\mathrm{No}^{\mathrm{r}}$ & $106(46.1)$ & $230(100)$ & & & \\
\hline Yes & $42(67.7)$ & $62(100)$ & $0.002 *$ & $0.003^{*}$ & $2.457(1.359-4.442)$ \\
\hline \multicolumn{6}{|c|}{ BECAME COVID POSITIVE AFTER COVIDDUTY } \\
\hline $\mathrm{No}^{\mathrm{r}}$ & $134(50.2)$ & $267(100)$ & & & \\
\hline Yes & $14(56)$ & $25(100)$ & 0.578 & 0.579 & $1.263(0.553-2.883)$ \\
\hline \multicolumn{6}{|c|}{ SLEEP DISBURBANCES } \\
\hline $\mathrm{No}^{\mathrm{r}}$ & $60(36.8)$ & 163(100) & & & \\
\hline Yes & $88(68.2)$ & $129(100)$ & $0.000^{*}$ & $0.000^{*}$ & $3.685(2.261-6.006)$ \\
\hline \multicolumn{6}{|c|}{ FALL ASLEEP IF WAKE UP IN NIGHT } \\
\hline Yes $^{r}$ & $102(49.8)$ & 205(100) & & & \\
\hline No & $52(52.9)$ & $87(100)$ & 0.626 & 0.626 & $1.133(0.686-1.872)$ \\
\hline \multicolumn{6}{|c|}{ QUALITY OF SLEEP AFFECT THE NEXT FUNCTION } \\
\hline $\mathrm{No}^{\mathrm{r}}$ & $21(25.6)$ & $82(100)$ & & & \\
\hline Yes & $127(60.5)$ & $210(100)$ & $0.000 *$ & $0.000^{*}$ & $4.445(2.519-7.842)$ \\
\hline
\end{tabular}

*- significant p-value $(<0.05)$.

${ }^{\mathrm{r}}$ Reference group.

Table 4 shows that Depression, Anxiety, Stress were positively correlated with the number of COVID duties and number of elder persons present in their family ( $\mathrm{p}$ value $<0.05$ ). As the number of duties and number of elder persons in the family increased, the depression, anxiety, stress scores were also increased among the doctors. All three parameters were negatively correlated with sleep duration and study participants attitude towards COVID 19 ( $\mathrm{p}$ value $<0.05$ ). All scores were increased among those who had less duration of sleep and those who had negative attitude towards COVID 19. Stress score was positively correlated with age which was statistically significant.

Table 5 shows multiple logistic regression analysis of various factors associated with depression, anxiety and stress. In binary logistic regression analysis, educational qualification, type of specialty, symptoms developed after COVID duty, sleep disturbances, poor quality of sleep affecting next day function were risk factors predicted to be significantly associated with depression, anxiety and stress. In addition to that factors like not attended training before their COVID duty, doctors with chronic medical illness were predicted to be significantly associated with depression and stress respectively. Factors which were statistically significant in binary logistic regression were analyzed in multivariate logistic regression and adjusted odds ratios were calculated. Risk of developing depression was predicted to be significantly higher among postgraduates both clinical and nonclinical (odd's ratio $=5.432(1.507-19.585), 1.876(1.018-3.457)$ ), among those with sleep disturbances (odd's ratio $=4.005(2.323-6.905)$ ) and those with poor quality of sleep affecting the next day function (odd's ratio $=3.425$ (1.705-6.881)) than their counterparts. Risk of developing anxiety, stress were predicted to be significantly higher among those with sleep disturbances (odd's ratio $=2.758(1.636-4.649)$, 3.246(2.029-5.786)) and those with poor quality of sleep affecting the next day function (odd's ratio $=2.942(1.608-5.383)$, 3.043(1.590-5.820)) than those without sleep disturbances and good quality of sleep respectively.

\section{Discussion}

The present study result revealed that $42.1 \%$ of study participants had depression, $43.8 \%$ had stress, and $50.7 \%$ had anxiety which is high compared to other studies done in India. ${ }^{8,10,17}$ This study has been done exclusively among doctors in tertiary care hospital. So the number of severe and sick cases might have been more in the present study setting leading to increase in challenging situations and workload among doctors, justifying the higher prevalence. Females had higher proportion ( $45.5 \%$ of depression, $54.5 \%$ of anxiety, and $45.5 \%$ of stress) of psychological impact. However this was not statistically significant. Other studies done by Wilson et al. Lai et al., Shaukat et al. Imran $\mathrm{N}$ et al. showed statistically significant proportion of psychological morbidity among females. ${ }^{18-21}$ Mean age of the study participants was 25.98 yrs. The present study results showed that old age was significantly associated with stress but not with depression and anxiety. This was similar to study done by Liang et al. where no statistically significant association was found between age and depressive symptoms.

In the present study participants, postgraduates had more prevalence of psychological morbidity than undergraduates which was statistically significant. Studies done by Wang et al. Gupta et al. also showed higher prevalence psychological impact among postgraduates. ${ }^{22,31}$ This may be because postgraduates might had more responsibility in looking after COVID-19 units, intensive care units, thus perhaps being more exposed to patients leading to more psychological impacts in them than undergraduates.

Risk of anxiety and stress among the married persons was slightly 
Table 3

Association between Stress and Various Risk factors among study participants $(\mathrm{n}=292)$.

\begin{tabular}{|c|c|c|c|c|c|}
\hline FACTORS & STRESS $\mathrm{n}=128(\%)$ & TOTAL n = 292(\%) & $\begin{array}{l}\text { CHI-SQUARE P- } \\
\text { VALUE }\end{array}$ & $\begin{array}{l}\text { P- VALUE BY BINARY LOGISTIC } \\
\text { REGRESSION }\end{array}$ & $\begin{array}{l}\text { UNADJUSTED ODD'S RATIO ( } 95 \% \\
\text { CI) }\end{array}$ \\
\hline \multicolumn{6}{|l|}{ GENDER } \\
\hline Male $^{r}$ & $58(42)$ & $138(100)$ & & & \\
\hline Female & $70(45.5)$ & $154(100)$ & 0.556 & 0.556 & $1.149(0.723-1.827)$ \\
\hline \multicolumn{6}{|c|}{ EDUCATIONAL QUALIFICATION } \\
\hline Undergraduate $^{r}$ & $33(34)$ & $97(100)$ & & & \\
\hline Postgraduate & $95(48.7)$ & 195(100) & $0.017^{*}$ & $0.018^{*}$ & $1.842(1.112-3.054)$ \\
\hline \multicolumn{6}{|c|}{ TYPE OF SPECIALITY } \\
\hline Clinical & $85(47.8)$ & $178(100)$ & & & \\
\hline Nonclinical & $10(58.8)$ & $17(100)$ & & 0.058 & $2.771(0.996-7.943)$ \\
\hline Undergraduates $^{r}$ & $33(34)$ & $97(100)$ & $0.042^{*}$ & $0.029^{*}$ & $1.773(1.061-2.960)$ \\
\hline \multicolumn{6}{|c|}{ MARITAL STATUS } \\
\hline Unmarried $^{r}$ & $102(43.8)$ & $233(100)$ & & & \\
\hline Married & $26(44.1)$ & $59(100)$ & 0.968 & 0.968 & $1.012(0.569-1.799)$ \\
\hline \multicolumn{6}{|c|}{ H/O CHRONIC MEDICAL ILLNESS } \\
\hline $\mathrm{No}^{\mathrm{r}}$ & $116(42.5)$ & $273(100)$ & & & \\
\hline Yes & $12(63.2)$ & $19(100)$ & 0.079 & 0.087 & $2.320(0.886-6.075)$ \\
\hline \multicolumn{6}{|c|}{ COVID TRAINING BEFORE DUTY } \\
\hline Yes $^{\mathrm{r}}$ & $120(42.7)$ & 281(100) & & & \\
\hline No & $8(72.7)$ & $11(100)$ & $0.049^{*}$ & 0.064 & $3.578(0.93013 .771)$ \\
\hline \multicolumn{6}{|c|}{ DEVELOP SYMPTOMS AFTER COVIDDUTY } \\
\hline $\mathrm{No}^{\mathrm{r}}$ & $91(39.6)$ & $230(100)$ & & & \\
\hline Yes & $37(59.7)$ & $62(100)$ & $0.005^{*}$ & $0.005^{*}$ & $2.261(1.276-4.006)$ \\
\hline \multicolumn{6}{|c|}{ BECAME COVID POSITIVE AFTER COVIDDUTY } \\
\hline $\mathrm{No}^{\mathrm{r}}$ & $116(43.4)$ & $267(100)$ & & & \\
\hline Yes & $12(48)$ & $25(100)$ & 0.661 & 0.661 & $1.202(0.529-2.731)$ \\
\hline \multicolumn{6}{|c|}{ SLEEP DISBURBANCES } \\
\hline $\mathrm{No}^{\mathrm{r}}$ & $46(28.2)$ & $163(100)$ & & & \\
\hline Yes & $82(63.6)$ & $129(100)$ & $0.000^{*}$ & $0.000^{*}$ & $4.438(2.705-7.279)$ \\
\hline \multicolumn{6}{|c|}{ FALL ASLEEP IF WAKE UP IN NIGHT } \\
\hline Yes $^{r}$ & $88(42.9)$ & 205(100) & & & \\
\hline No & $40(46)$ & $87(100)$ & 0.631 & 0.631 & $1.132(0.683-1.873)$ \\
\hline \multicolumn{6}{|c|}{ QUALITY OF SLEEP AFFECT THE NEXT FUNCTION } \\
\hline $\mathrm{No}^{\mathrm{r}}$ & $16(19.5)$ & $82(100)$ & & & \\
\hline Yes & $112(53.3)$ & $210(100)$ & $0.000^{*}$ & $0.000^{*}$ & $4.714(2.562-8.674)$ \\
\hline
\end{tabular}

*- significant p-value $(<0.05)$.

${ }^{\mathrm{r}}$ Reference group.

Table 4

Correlation between continous variables and depression, anxiety, stress scores.

\begin{tabular}{|c|c|c|c|c|c|c|}
\hline \multirow[t]{2}{*}{ VARIABLE } & \multicolumn{2}{|c|}{ DEPRESSION } & \multicolumn{2}{|c|}{ ANXIETY } & \multicolumn{2}{|l|}{ STRESS } \\
\hline & $\begin{array}{l}\text { R- } \\
\text { VAUE }\end{array}$ & SIG. & $\begin{array}{l}\text { R- } \\
\text { VAUE }\end{array}$ & SIG. & $\begin{array}{l}\text { R- } \\
\text { VAUE }\end{array}$ & SIG. \\
\hline AGE & 0.106 & 0.071 & 0.077 & 0.187 & 0.153 & $0.009 *$ \\
\hline $\begin{array}{l}\text { NUMBER OF } \\
\text { COVID } \\
\text { DUTIES }\end{array}$ & 0.163 & $0.005^{*}$ & 0.138 & $0.018^{*}$ & 0.133 & $0.023^{*}$ \\
\hline $\begin{array}{l}\text { DURATION } \\
\text { BETWEEN } \\
\text { DUTIES }\end{array}$ & -0.098 & 0.093 & -0.033 & 0.571 & -0.075 & 0.200 \\
\hline $\begin{array}{l}\text { SLEEP } \\
\text { DURATION }\end{array}$ & -0.219 & $0.000 *$ & -0.281 & $0.000^{*}$ & -0.239 & $0.000 *$ \\
\hline $\begin{array}{l}\text { ATTITUDE } \\
\text { SCORE }\end{array}$ & -0.319 & $0.000^{*}$ & -0.274 & $0.000^{*}$ & -0.291 & $0.000 *$ \\
\hline $\begin{array}{l}\text { NO OF } \\
\text { CHILDREN }\end{array}$ & 0.082 & 0.165 & 0.098 & 0.095 & 0.090 & 0.125 \\
\hline $\begin{array}{l}\text { NO OF ELDER } \\
\text { PERSONS }\end{array}$ & 0.188 & $0.001^{*}$ & 0.169 & $0.004 *$ & 0.188 & $0.001 *$ \\
\hline
\end{tabular}

*- significant p-value $(<0.05)$.

higher than unmarried persons which were not statistically significant. But Jain et al. and Dai et al. studies showed significant association between marital status and anxiety. Similar to Vaibhav et al. Banerjee et al. studies, the present study also predicted that doctors with pre-existing comorbidities had a statistically significantly higher risk of developing psychological impact (63.2\%of depression, $78.9 \%$ of anxiety, $63.2 \%$ of stress) $)^{12,23}$ than those without comorbidities. This may be because of their fear of self-infection and disease severity which would have made them susceptible to psychological impact. The present study predicted that presence of elder persons in their family was a significant risk factor for psychological impact but the presence of children in their family was not the risk factor. In contrast to this, study done by Elbay et al. found out that having a child was associated with lower DASS scores. ${ }^{30}$ Elderly population are immune compromised and they are more prone for acquisition of any infection, their presence in home might have increased the psychological impacts among doctors due to fear of transmitting infection to them. Number of COVID duties done by doctors are also an important risk factor predicted to increase the psychological impact in our survey. Another study done in India also reported that long working hours further increase the risk of stress among the doctors. ${ }^{10}$ Increase in working hours, increases the fear of acquisition of COVID infection due to increase in duration of exposure. It also increases the work load making the doctors more prone for psychological impact.

In the present study, $8.6 \%$ of doctors became COVID positive after their COVID duty which is comparatively higher than $2.6 \%$ in an another Indian study done by Chatterjee et al. ${ }^{17}$ In the present study among those who had sleep disturbances $63.6 \%$ were depressed, $68.2 \%$ were anxious, and $63.6 \%$ were stressed. In an another study done in India among health care workers by Gupta et al. poor quality of sleep was associated with higher anxiety level(p value $-<0.001){ }^{22}$ Another observational study involving 180 medical staff dealing directly with COVID-19 patients also showed the substantial effect of stress and anxiety on the sleep quality. ${ }^{27}$

The present study results predicted that depression and stress was found to be high in those who have not attended COVID training before COVID duty. Naushed et al. study also reported that lack of training was one among the risk factors for developing psychological morbidities. ${ }^{24,28}$ Another important finding in this study was that psychological comorbidities were less prevalent in those with positive attitude. ${ }^{29}$ Like 
Table 5

Factors associated with depression, anxiety, stress using multivariate logistic regression $(\mathrm{N}=292)$.

\begin{tabular}{|c|c|c|c|c|c|c|c|c|c|}
\hline \multirow[t]{2}{*}{ FACTORS } & \multicolumn{3}{|c|}{ DEPRESSION } & \multicolumn{3}{|c|}{ ANXIETY } & \multicolumn{3}{|l|}{ STRESS } \\
\hline & $\begin{array}{l}\mathrm{p}- \\
\text { value }\end{array}$ & $\begin{array}{l}\text { Unadjusted odd's } \\
\text { ratio }(95 \% \mathrm{CI})\end{array}$ & $\begin{array}{l}\text { Adjusted odd's } \\
\text { ratio }(95 \% \mathrm{CI})\end{array}$ & $\begin{array}{l}\text { p- } \\
\text { value }\end{array}$ & $\begin{array}{l}\text { Unadjusted odd's } \\
\text { ratio }(95 \% \mathrm{CI})\end{array}$ & $\begin{array}{l}\text { Adjusted odd's } \\
\text { ratio }(95 \% \mathrm{CI})\end{array}$ & $\begin{array}{l}\mathrm{p}- \\
\text { value }\end{array}$ & $\begin{array}{l}\text { Unadjusted odd's } \\
\text { ratio ( } 95 \% \mathrm{CI})\end{array}$ & $\begin{array}{l}\text { Adjusted odd's } \\
\text { ratio }(95 \% \mathrm{CI})\end{array}$ \\
\hline \multicolumn{10}{|c|}{ Educational qualification } \\
\hline Undergraduate $^{r}$ & & 2.514 & 1.876 & & 1.661 & 1.171 & & 1.842 & 1.438 \\
\hline $\begin{array}{l}\text { Postgraduate } \\
\text { Speciality }\end{array}$ & $0.044^{*}$ & $(1.487-4.251)$ & $(1.018-3.457)$ & 0.583 & $(1.016-2.716)$ & $(0.666-2.058)$ & 0.219 & $(1.112-3.054)$ & $(0.806-2.568)$ \\
\hline \multicolumn{10}{|l|}{ Undergraduates ${ }^{r}$} \\
\hline Clinical & $0.010^{*}$ & $\begin{array}{l}6.222 \\
(2.002-19.336)\end{array}$ & $\begin{array}{l}5.432 \\
(1.507-19.585)\end{array}$ & 0.171 & $\begin{array}{l}3.278 \\
(1.071-10.03)\end{array}$ & $\begin{array}{l}2.363 \\
(0.690-8.087)\end{array}$ & 0.193 & $\begin{array}{l}2.771 \\
(0.996-7.943)\end{array}$ & $\begin{array}{l}2.147 \\
(0.679-6.795)\end{array}$ \\
\hline Nonclinical & $0.044^{*}$ & $\begin{array}{l}2.317 \\
(1.360-3.947)\end{array}$ & $\begin{array}{l}1.876 \\
(1.018-3.457)\end{array}$ & 0.583 & $\begin{array}{l}1.563 \\
(0.949-2.575)\end{array}$ & $\begin{array}{l}1.171 \\
(0.666-2.058)\end{array}$ & 0.219 & $\begin{array}{l}1.773 \\
(1.061-2.960)\end{array}$ & $\begin{array}{l}1.438 \\
(0.865-2.568)\end{array}$ \\
\hline \multicolumn{10}{|l|}{ Training attended } \\
\hline No & 0.072 & $\begin{array}{l}6.592 \\
(1.398-31.076)\end{array}$ & $\begin{array}{l}4.866 \\
(0.869-27.248)\end{array}$ & 0.151 & $\begin{array}{l}2.686 \\
(0.698-10.333)\end{array}$ & $\begin{array}{l}\text { Not significant in } \\
\text { Univariate } \\
\text { analysis }\end{array}$ & 0.064 & $\begin{array}{l}3.578 \\
(0.930-13.771)\end{array}$ & $\begin{array}{l}\text { Not significant in } \\
\text { Univariate } \\
\text { analysis }\end{array}$ \\
\hline \multicolumn{9}{|c|}{ Chronic Medical Illness } & \\
\hline Present & 0.062 & $\begin{array}{l}2.502 \\
(0.955-6.553)\end{array}$ & $\begin{array}{l}\text { Not significant in } \\
\text { Univariate } \\
\text { analysis }\end{array}$ & 0.280 & $\begin{array}{l}3.947 \\
(1.277-12.197)\end{array}$ & $\begin{array}{l}1.966 \\
(0.576-6.713)\end{array}$ & 0.087 & $\begin{array}{l}2.320 \\
(0.886-6.075)\end{array}$ & $\begin{array}{l}\text { Not significant in } \\
\text { Univariate } \\
\text { analysis }\end{array}$ \\
\hline \multicolumn{10}{|c|}{ Developed symptoms after COVID duty } \\
\hline Yes & 0.154 & $\begin{array}{l}2.276 \\
(1.286-4.026)\end{array}$ & $\begin{array}{l}1.619 \\
(0.834-3.144)\end{array}$ & 0.071 & $\begin{array}{l}2.457 \\
(1.359-4.442)\end{array}$ & $\begin{array}{l}1.852 \\
(0.950-3.610)\end{array}$ & 0.097 & $\begin{array}{l}2.261 \\
(1.276-4.006)\end{array}$ & $\begin{array}{l}1.728 \\
(0.905-3.298)\end{array}$ \\
\hline \multicolumn{10}{|c|}{ Sleep disturbances } \\
\hline Present & $0.000^{*}$ & $\begin{array}{l}5.191 \\
(3.317-8.591)\end{array}$ & $\begin{array}{l}4.005 \\
(2.323-6.905)\end{array}$ & $0.000^{*}$ & $\begin{array}{l}3.685 \\
(2.261-6.006)\end{array}$ & $\begin{array}{l}2.758 \\
(1.636-4.649)\end{array}$ & $0.000^{*}$ & $\begin{array}{l}4.438 \\
(2.705-7.279)\end{array}$ & $\begin{array}{l}3.246 \\
(2.029-5.786)\end{array}$ \\
\hline \multicolumn{10}{|c|}{$\begin{array}{l}\text { Quality of sleep affect the next day function } \\
\text { No }^{r}\end{array}$} \\
\hline Yes & $0.001^{*}$ & $\begin{array}{l}5.242 \\
(2.776-9.899)\end{array}$ & $\begin{array}{l}3.425 \\
(1.705-6.881)\end{array}$ & $0.000^{*}$ & $\begin{array}{l}4.445 \\
(2.519-7.842)\end{array}$ & $\begin{array}{l}2.942 \\
(1.608-5.383)\end{array}$ & $0.001^{*}$ & $\begin{array}{l}4.714 \\
(2.562-8.674)\end{array}$ & $\begin{array}{l}3.043 \\
(1.590-5.820)\end{array}$ \\
\hline
\end{tabular}

*-Statistically significant.

${ }^{\mathrm{r}}$ Reference categories.

other previous studies done during various epidemics such as MERS, our study also found out that significant proportion of doctors had fear of self-infection (74\%), possibility of being a source of infection $(82.2 \%)$, but in contrast to previous studies HCW's in our study were more satisfied about the quality of PPE. ${ }^{25,26}$

Strengths of the present study were use of a validated tool for screening the psychological impact of study participants and it was exclusively done among doctors (undergraduates and postgraduates) who were directly involved in clinical care of the patient.

But however this study was conducted in tertiary care hospital in Madurai, which limits its generalisation to all doctors in community. Some of the responders might not heartfelt in providing information about their psychological problems that might have also affected the study results.

\section{Conclusion}

Significantly high proportions of doctors were affected psychologically by the COVID-19 crisis. Postgraduates, Doctors with chronic medical illness, elderly persons in their family were more prone to psychological impact. Increased number of COVID duties, sleep disturbances, duration of sleep significantly affected the mental health of doctors. All these necessitates the provision of training regarding recent treatment protocols of COVID 19; donning and doffing techniques and other infection control measures; family support; psychological counselling. Doctors with comorbidities can be considered for exemption from COVID duty to reduce the burden of psychological problems among them. Therefore the present study can provide base for further studies and guide the policy makers to provide guidelines for early screening and implementation of intervention programme for mental wellbeing of HCW's.

\section{Financial interest}

None.

\section{Funding}

This research did not receive any specific grant from funding agencies in the public, commercial or not-for- profit sectors.

\section{Data integrity}

Dataset is under the control of our institution, but it can be provided through proper channel upon requisition to corresponding author.

\section{Submission declaration}

This work is not published previously or considered for publication. Publication is approved by all authors and by responsible authuroities where work has been carried out. If accepted it will not be published elsewhere in the same form without written consent of copyright holder.

\section{Declaration of competing interest}

The authors declare that they have no competing interests.

\section{Acknowledgement}

We thank our Dean.Professor Dr. J.Sangumani for his motivation to do this study. We also thank all Post graduates and CRRI's of the Institute of Community Medicine who helped us in data collection. 


\author{
Abbrevations \\ SARS Severe Acute Respiratory Syndrome \\ MERS Middle East Respiratory Syndrome \\ COVID-19 Corona Virus Disease-19 \\ WHO World Health Organization \\ HCW Health Care Worker \\ PPE Personal Protective Equipment \\ CRRI Compulsory Rotatory Residential Internship \\ PG Post Graduate \\ UG Under Graduate \\ DASS-21 Depression Anxiety Stress Scale-21 \\ SPSS Statistical Package for the Social Science
}

\section{References}

1 Jamie Ducharme. The WHO just declared coronavirus COVID-19 a pandemic. Available from: https://time.com/5791661/who-coronavirus-pandemic-declaratio n/; 2020 Mar; 11. Accessed January 22, 2021.

2 WHO Coronavirus (COVID-19) Dashboard; 2020 Mar; 11. Available from: http s://covid19.who.int. Accessed January 22, 2021

3 MoHFW. Home. Available from: https://www.mohfw.gov.in/; 2020 Mar; 11. Accessed January 22, 2021.

4 Xiang YT, Yang Y, Li W, et al. Timely mental health care for the 2019 novel coronavirus outbreak is urgently needed. Lancet Psychiatr. 2020 Mar 1;7(3):228-229.

5 Mahase E. Coronavirus COVID-19 has killed more people than SARS and MERS combined, despite lower case fatality rate. BMJ. 2020;368:m641.

6 Wu KK, Chan SK, Ma TM. Posttraumatic stress, anxiety, and depression in survivors of severe acute respiratory syndrome (SARS). J Trauma Stress: Official Pub Int So Trauma Stress Stud. 2005 Feb;18(1):39-42 (1).

7 Lancee WJ, Maunder RG, Goldbloom DS. Prevalence of psychiatric disorders among toronto hospital workers one to two years after the SARS outbreak. Psychiatr Serv. 2008 Jan;59(1):91-95.

8 Khanna RC, Honavar SG, Metla AL, Bhattacharya A, Maulik PK. Psychological impact of COVID-19 on ophthalmologists-in-training and practising ophthalmologists in India. Indian J Ophthalmol. 2020 Jun;68(6):994.

9 Liu S, Yang L, Zhang C, et al. Online mental health services in China during the COVID-19 outbreak. Lancet Psychiatr. 2020 Apr 1;7(4):e17-e18.

10 Selvaraj P, Muthukanagaraj P, Saluja B, et al. Psychological impact of COVID-19 pandemic on health-care professionals in India - a multicentric cross-sectional study. Indian J Med Sci, doi: 10.25259/IJMS_193_2020.

11 Raj R, Koyalada S, Kumar A, Kumari S, Pani P, Singh KK. Psychological impact of the COVID-19 pandemic on healthcare workers in India: an observational study. J Fam Med Prim Care. 2020 Dec 1;9(12):5921.

12 Banerjee D, Vaishnav M, Rao TS, et al. Impact of the COVID-19 pandemic on psychosocial health and well-being in South-Asian (World Psychiatric Association zone 16) countries: a systematic and advocacy review from the Indian Psychiatric Society. Indian J Psychiatr. 2020 Sep;62(Suppl 3):S343.

13 Antony MM, Bieling PJ, Cox BJ, Enns MW, Swinson RP. Psychometric properties of the 42-item and 21-item versions of the Depression Anxiety Stress Scales in clinical groups and a community sample. Psychol Assess. 1998 Jun;10(2):176-181.
14 Ng F, Trauer T, Dodd S, Callaly T, Campbell S, Berk M. The validity of the 21-item version of the Depression Anxiety Stress Scales as a routine clinical outcome measure. Acta Neuropsychiatr. 2007 Oct;19(5):304-310.

15 Chan RC, Xu T, Huang J, et al. Extending the utility of the Depression Anxiety Stress scale by examining its psychometric properties in Chinese settings. Psychiatr Res. 2012 Dec 30;200(2-3):879-883.

16 Musa R, Fadzil MA, Zaini Z. Translation, validation and psychometric properties of Bahasa Malaysia version of the depression anxiety and stress scales (DASS) ASEAN. J Psychiatr. 2007;82:82-89.

17 Chatterjee SS, Bhattacharyya R, Bhattacharyya S, Gupta S, Das S, Banerjee BB. Attitude, practice, behavior, and mental health impact of COVID-19 on doctors. Indian J Psychiatr. 2020 May;62(3):257.

18 Wilson W, Raj JP, Rao S, et al. Prevalence and predictors of stress, anxiety, and depression among healthcare workers managing COVID-19 pandemic in India: a nationwide observational study. Indian J Psychol Med. 2020 Jul;42(4):353-358.

19 Lai J, Ma S, Wang Y, et al. Factors associated with mental health outcomes among health care workers exposed to coronavirus disease 2019. JAMA network open. 2020 Mar 2;3(3), e203976.

20 Shaukat N, Ali DM, Razzak J. Physical and mental health impacts of COVID-19 on healthcare workers: a scoping review. Int J Emerg Med. 2020 Dec;13(1):1-8.

21 Imran N, Masood HM, Ayub M, Gondal KM. Psychological impact of COVID-19 pandemic on postgraduate trainees: a cross-sectional survey. Postgrad Med. 2020 Aug 25:138364.

22 Gupta S, Kohli K, Padmakumari P, et al. Psychological health among armed forces doctors during COVID-19 pandemic in India. Indian J Psychol Med. $2020 \mathrm{Jul} ; 42(4)$ 374-378.

23 Vaibhav K, Priya A, Gupta P. Psychological impact of COVID-19 on doctors and medical undergraduate students in a government medical college in Uttar Pradesh, India. Int J Commun Med Pub Health. 2020 Nov 25;7(12):4781.

24 Naushad VA, Bierens JJ, Nishan KP, et al. A systematic review of the impact of disaster on the mental health of medical responders. Prehospital Disaster Med. 2019 Dec 1;34(6):632-643.

25 Rossi R, Socci V, Pacitti F, et al. Mental health outcomes among frontline and secondline health care workers during the coronavirus disease 2019 (COVID-19) pandemic in Italy. JAMA network open. 2020 May 1;3(5), e2010185.

26 Khalid I, Khalid TJ, Qabajah MR, Barnard AG, Qushmaq IA. Healthcare workers emotions, perceived stressors and coping strategies during a MERS-CoV outbreak. Clin Med Res. 2016 Mar 1;14(1):7-14.

27 Xiao H, Zhang Y, Kong D, Li S, Yang N. The effects of social support on sleep quality of medical staff treating patients with coronavirus disease 2019 (COVID-19) in January and February 2020 in China. Med Sci Mon Int Med J Exp Clin Res: Int Med J Exp Clin Res. 2020;26. e923549-1.

28 Sharma A, Aswal MR, Gupta R. Assessment of knowledge, attitude and practice regarding COVID-19 pandemic among health care professionals: a cross-sectional study. J Clin Diagn Res. 2020 sep;14(9):5-10.

29 DaiY, Hu G, XiongH QiuH, Yuan X. Psychological impact of the coronavirus disease 2019 (COVID-19) outbreak on healthcare workers in China. MedRxiv. 2020 March 6: 20030874.

30 Elbay RY, Kurtulmuş A, Arpacıoğlu S, Karadere E. Depression, anxiety, stress levels of physicians and associated factors in Covid-19 pandemics. Psychiatr Res. 2020 Aug 1;290:113130.

31 Wang Y, Li Y, Jiang J, et al. COVID-19 outbreak-related psychological distress among healthcare trainees: a cross-sectional study in China. BMJ open. 2020 Oct 1;10 (10), e041671. 